\title{
Reliability Evaluation of Compaction Water Content of Plantain Peel Ash Treated Lateritic Soil
}

\author{
K. Ishola ${ }^{1}$, O. A. Olawuyi ${ }^{1}$, P. Yohanna ${ }^{2}$, A. A. Bello ${ }^{1}$, R.O. Sani ${ }^{3}$, O. O. Akin ${ }^{4}$ \\ ${ }^{1}$ Department of Civil Engineering, Osun State University, Osogbo, Osun State, Nigeria. \\ ${ }^{2}$ Department of Civil Engineering, University of Jos, Plateau State, Nigeria. \\ ${ }^{3}$ Department of Civil Engineering, Covenant Univerity, Ota Ogun State, Nigeria \\ ${ }^{4}$ Department of Civil Engineering, Ahmadu Bello University Zaria, Kaduna State, Nigeria.
}

\begin{abstract}
A first-order reliability method (FORM)was employed to assess the compaction water content, CWC (i.e optimum moisture content) of residual lateritic soil mixed with plantain peel ash (PPA) and compacted with British Standard Light (BSL)and British Standard Heavy (BSH)energies, for flexible pavement applications. A Multi-linear regression model was generated from values obtained via laboratory tests using Mini-tab R15 software, which served as a performance function that was applied for the analysis. Using the regression models for CWC, established distributions for the relevant soil factors, safety index (SI) was computed using CWC as a dependent factor and the soil factors Plantain Peel Ash (PPA); Plasticity Index (PI); Percentage File (PF); Specific Gravity (Gs) and Compactive Effort (CE)as self-determining factors). The results revealed that the safety index is sensitive to changeability in the soil factors. Outcome from the analysis show that Gs and CE are greatly affected by alteration in the coefficient of variation (COV), and so it is essential to control Gs and CE in lateritic soil-PPA mixes in road pavements. From the safety index values it reveals that PPA content has a minimal consequence as its value virtually remained constant at all COV used. Stochastically, lateritic soil mixed with PPA produces an acceptable safety index value of 1.0, as mentioned by the Nordic Committee on Building Regulation (NCBR) at 10\% COV for BSH of compaction water content only. Therefore a more effective additive such as cement, lime, or bitumen is recommended for modeling CWC of lateritic soil-PPA mixes for road pavement at 10-100\% series of COV.
\end{abstract}

KEYWORDS: Coefficient of variation; compaction water content; lateritic soil; plantain peel ash; reliability index

[Received Aug. 12, 2020; Revised Jan. 01, 2021; Accepted Feb. 07, 2021]

Print ISSN: 0189-9546 | Online ISSN: 2437-2110

\section{INTRODUCTION}

Lateritic soils are reddish tropically pedogenic deposits occurring in many nations like Australia, Asia, Africa, and South America. Lateritic soils are the outcome of tropical or sub-tropical weathering. Gidigasu, (1976), Sherman (1952), Maigen (1966), Muhammad and Yamusa, (2013), ishola et al., (2019) and Etim et al., (2020) in their findings, reported on the two sets of these tropical soils chemically identified by those in which iron oxide is predominant (ferruginous laterite) and those in which alumina oxide is predominant (aluminous laterite). In tropical nations like Nigeria, lateritic gravels, as well as pisoliths, are predominantly available and this has been observed to be essential for gravel roads purposes as contained in the literatures (Osinubi and Bajeh, 1994; Muhammad and Yamusa, 2013; Etim et al., (2020; Yohanna and Nwaiwu, 2021) and used widely as base material and equally as a subbase material for roads to be subjected for medium or low traffic. Laterites are categorized as problem soil and nonproblem soil. The problematic one is characterised by swelling, *Corresponding author: isholakzm@gmail.com depressions, and lateral movement because of moisture effect or impact of wheel loads (Obeahon, 1993; Yohanna and Nwaiwu, 2021). The need to improve deficient lateritic soil is of paramount significance in other to achieve durable pavement and in other engineering applications such as landfills, embankments etc.

The conventional additives for improving deficient soils entail the use of industrially produced additives such as lime, cement, bitumen etc. However, high cost of additives like cement and lime yielded to consideration of agricultural waste such as plantain peel ash (PPA), waste wood ash (WWA), etc on the properties of unsuitable soils for use in engineering applicatons like roads. Agricultural waste exhibiting pozzalanic behaviour was applied and yielded great level of success in many engineering works (Oluremi, 2015; Osinubi, et al., 2017). Research has been on-going on the possibility of using agricultural waste like sawdust ash (SDA), rice husk ash (RHA), bagasse ash (BA) etc. because their pozzolanic behaviour in treatment of deficient soils have recorded positive results (Phanikumar, 2004; Moses, 2008; Moses and Folagbade, 2010; Eberemu, 2011; Sani, 2012; Yohanna et al., doi: http://dx.doi.org/10.4314/njtd.v18i1.7 
2016; Osinubi et al., 2015; Etim et al., 2017).The increasing price tag of these additives has remained a problem and the enhancement of lateritic soil with PPA having pozzalanic property may be relatively cheaper.

A reliability evaluation of a structure in engineering is welldefined as the assurance on its capacity to achieve its design determination within a specified time (Dey and Kudmetha, 2013). Reliability evaluation are founded on the probability philosophies which provide the platform for its measurement. The reliability of a system can be regarded as the likelihood of its acceptable performance based on certain given performance functions. This function is for a definite purpose and it is laid open to extreme settings within a given time (Dey and Kudmetha, 2013). Several kinds of research (Harrop-Willians, 1985; Gui et al., 2000; Eberemu, 2008; Nwaiwu et al., 2009; Yisa and Sani, 2014; Oluremi et al., 2018) reported on reliability applications in geotechnical engineering for design with respect to varying rock and soil properties. Past researches (Nwaiwu et al, 2009; Yisa and Sani, 2014; Sani et al, 2014; 2017; Yohanna et al, 2018) made use of mathematical tools like the probability principle to define uncertainties in engineering design and weigh their consequences on field performance. These approaches are been used in assessing structural and geotechnical requirements like reliability estimate of strength and compaction properties, bearing capacity etc.

A FORM integrated in FORTRAN program was used to appraise the effect of compaction water content(CWC) on lateritic soil - PPA mixes. The aim is to generate safety index values for compaction water content (CWC) with respect to the soil self-determining variables. The objective was to determine the variability in safety index values base on laboratory- based model with respect to all the soil parameters.

\section{A. Safety Factor}

The elementary method for weighing the factor of safety (Safety factor) of a system in engineering was established on its permissible factor of safety determined on the basis of the particular opinion of responses from related systems. Engineers developed a method for measuring the safety factor defined as the relation between assumed nominal standards of capacity $x$ and demand y (Kotegodaand Rosso, 1997, Duncan, 2000) as shown in Eq. (1).

$$
Z=\frac{x}{y}
$$

The variables $\mathrm{x}$ and $\mathrm{y}$ cannot be obtained with certainty, therefore are measured as probability distribution. Factor of safety designated by $\mathrm{z}=\mathrm{x} / \mathrm{y}$ with regard to the random variables $\mathrm{x}$ and $\mathrm{y}$ is similarly a random variable. The relationship between capacity $\mathrm{x}$ and demand $\mathrm{y}$ for the structure is defined as $z=x / y$. Probability $\operatorname{Pr}$ of a system of failure is explained as in Eq. (2).

$P_{T}=P_{T}(Z<1)-F_{2}$
$R=1-P_{T}(Z<1)=1-F_{2}$

After determining the combined probability distribution for variables $x$ and $y$, the safety index of the entire system can be calculated by defining the comulative distribution function of $x / y$. Assuming peak demand $Y_{\max }$ does not surpass the least capacity $X_{\min }$ then a chances of failure of zero $(\mathrm{pr}=0)$ and 100 percent reliability $(r=1)$ occurs. Under such condition, there is no overlapping of the two distributions (Oriola et al., 2012).

\section{B. Reliability/Safety Index}

The mathematical explanation for the safety index is presented in Eq. (4).

$$
\beta=\frac{\mu}{d}
$$

The index is defined as the competence of an engineering design deduced as the standard deviation $d$ within the average value of the safety margin.

$E(s)=\mu$

where its corresponding critical value $s$ is 0 .

The safety index ( $(3)$ is the relation of the mean and standard deviation of the system (Yisa and Sani, 2014). Alternatively, safety index is the inverse of COV of the safety margin, Thus $\beta=\mathrm{I} / \mathrm{Vs}$, as explained in literatures(Kottegoda and Rosso, 1997; Yisa and Sani 2014; Oluremi et al., 2018).

\section{First-Order Reliability Method (FORM)}

FORM is a deterministic and probabilistic design that differs in norm and engineering uses. Design problems comprise of component of several uncertainties. Probabilistic design is affected by the facts that a structure will agree with the functions assign to it to perform a design assignment (Afolayan and Abubakar, 2003).

For instance, let $r$ and $\mathrm{s}$ be strength capacity and the loading effect of a system which are random variables, the goal of reliability analysis is to certify that $r$ on no occasion is surpassed by s (Oriola et al, 2012). Therefore, $\mathrm{r}$ and $\mathrm{s}$ are generally functions of dissimilar parameters. In other to regulate the influence of the parameters on the behaviour of the system, a limit state equation (LSE) in relation to basic design factors is essential (Afolayan and Abubakar, 2003). This LSE is expressed as:

$g(t)=g\left(x_{1}, x_{2}, \ldots \ldots \ldots x_{n}\right)=r-s$

where $x_{1}$ for $i=1,2,3,4,5,6,7,8 \ldots n$, imply design factors.

The limit state for the system is explained by Eq. (7).

$G(t)=0$

The corresponding probability of nonfailure defined in Eq. (3). 


\section{MATERIALS AND METHODS}

Soil used for this work was sourced from Osogbo, Osun State, Nigeria. The plantain peels use was acquired from a dump site in Osun State. Plantain peels obtained was first air dried then burnt into ashes, followed by sieving through sieve No $200(0.075 \mathrm{~mm})$ to obtain plantain peel ash (PPA). The investigations on compaction water content, CWC (i.e optimum moisture content) and the parameters linked with water content of compaction were determined through the laboratory work. Soil sample was treated with $0,2,4,6,8$ and $10 \%$ PPA to determine the index and compaction behaviour of the mofified soil which aid in developing the regression equation in Eq. (9).

The various factors considered were; $\mathrm{CWC}$ as dependent factors and PPA; PI; PF; Gs and CE as self-determining factors. CWC and PI were presumed to be lognormally distributed while PPA; PF and Gs were assigned normal distributions. The performance function employed was integrated into a FORTRAN program, as suggested in previous works (Osinubi et al., 2016, Yohanna et al., 2018 ) used for the modelling the CWC. The prediction of safety indices for single parameter at a time was achieved within 10 to $100 \%$ COV whereas the original values for other factors remained unchanged. The multi-linear regression model was established by means of Minitab R15 (see Eq. (9)) used to predict CWC from the laboratory results. Reliability analysis input values are displayed in Table 1. The regression modelling equation for CWC is shown in Eq. (10).

$\mathrm{CW}=-1.1-0.044 \mathrm{PPA}+0.0278 \mathrm{PI}+0.0134 \mathrm{PF}+$ 4.524Gs1.758CE

$$
R^{2}=84.8 \%
$$

\section{RESULTS AND DISCUSSION}

The modelled Eq.(9) shows association amid the selfdetermining factors (PPA; PI; PF; Gs and CE) and the dependent factor (CWC). From the modelled, it can be inferred that, a good affiliation occurs between the self-determining factors and the CWC clearly evident by $84.8 \%$ regression coefficient recorded. From the established relationship, the engineering importance of this relation shows that the mentioned variables has a good effect on the CWC and thus need to be considered during performance to arrive at the required compaction density. Moisture control is considered as the proportion of compaction water added to the soil in the course of field compaction which alters the density and the corresponding structural strength of a flexible pavement. Morever, engineering performance and durability of roads cannot be properly explained outside the impact of the CWC which is greatly influenced by the factors in Eq. (9). It is thus of great significance to put these factors to use during field compaction of lateritic soil-PPA mixes to arrive at the required durable flexible pavemenet.
Table 1: Input data use for analysis.

\begin{tabular}{|c|c|c|c|c|c|}
\hline S/No & Variables & $\begin{array}{c}\text { Distribution } \\
\text { type }\end{array}$ & $\begin{array}{c}\text { Mean } \\
E(x)\end{array}$ & $\begin{array}{c}\text { Standard } \\
\text { Deviation } \\
S(x)\end{array}$ & $\begin{array}{l}\text { COV } \\
(\%)\end{array}$ \\
\hline 1 & $\begin{array}{l}\text { Compaction } \\
\text { Water }\end{array}$ & Lognormal & 11.09 & 2.002 & 1805 \\
\hline 2 & $\begin{array}{l}\text { Plantain } \\
\text { Peel Ash }\end{array}$ & Normal & 5.00 & 3.570 & 71.4 \\
\hline 3 & $\begin{array}{l}\text { Plasticity } \\
\text { Index }\end{array}$ & Lognormal & 21.62 & 4.870 & 22.53 \\
\hline 4 & $\begin{array}{l}\text { Percentage } \\
\text { Fine }\end{array}$ & Normal & 46.58 & 19.780 & 42.46 \\
\hline 5 & $\begin{array}{l}\text { Specific } \\
\text { Gravity }\end{array}$ & Normal & 2.47 & 0.044 & 1.78 \\
\hline 6 & $\begin{array}{l}\text { Compactive } \\
\text { Effort }\end{array}$ & $\begin{array}{l}\text { Deterministic } \\
\text { parameter }\end{array}$ & - & - & - \\
\hline
\end{tabular}

From Eq. (9), it can be observed that, increase in PPA and $\mathrm{CE}$, results to a drop in CWC values as a result of their negative coefficient while opposite is the situation for PI, PF and Gs with positive coefficients. Also, Gs and CE with high coefficients have considerable influence on the CWC when compared to other factors. The inference of the coefficients for the factors can be applied in the field to asses the performance on the road. The site engineer should therefore ensure strict adhenrence to these conditions as it will have great impact on the compacted density of the soil in the field and thus, consequently affect the structural strength and durability of the road pavement.

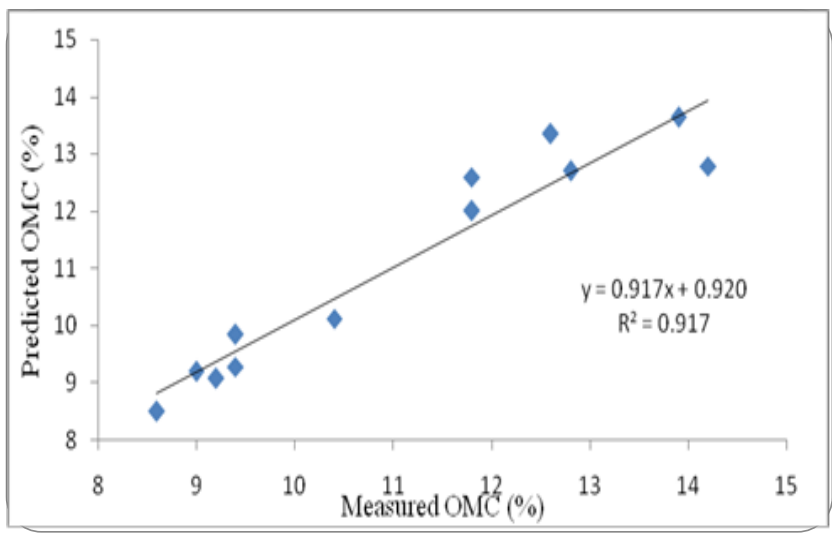

Figure 1: Predicted against measured CWC values.

The plot of affiliation between laboratory and predicted values from the model is shown in Figure 1. strong bond was recognized between them with a coefficient of determination of 0.9171 (Figure 1) and 0.721 to $9.918 \%$ errors (Table 2). The plot of CWC/Standardized coefficients (95\% confidence interval) with variables is shown in Figure 2. The plot shows the impact of every one of the self-determining factors to the compaction water content. 


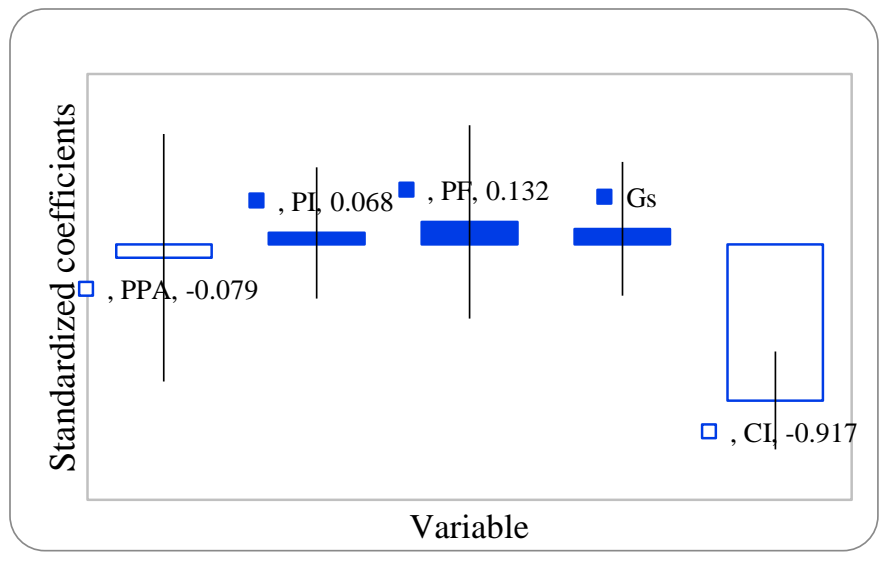

Figure 2: Plot of $\mathrm{CWC} /$ Standardized coefficients (95\% confidence interval) against Variable.

\section{A. Influence of Compaction Water Content on Safety Index}

The influence of compaction water content, CWC with safety index at $10-100 \% \mathrm{COV}$ is displayed in Figure 3. A linear declining trend was established with $10-100 \%$ range of COV for both BSL and BSH compaction energy. Although an initial increase was observed for BSL, it later decreased progressively with increase in COV. Safety indices varied substantially which is a signal that inconsistency in compaction water content has extreme impact on the safety index when used as pavement materials. As COV inclined from 10-100\%, $\beta$ values varied from -1.44 to -0.591 and -0.206 to 1.58 for BSL and $\mathrm{BSH}$ respectively. Lower safety index values were noted for BSL than BSH which indicate that compactive effort has significant influence on the optimum moisture required to achieve the desired result. Therefore, care should be taken to safeguard that proper compaction energy is applied in the field at a regulated amount of moisture to achieve the required density in the field during road construction.

\section{B. Influence of Plantain Peel Ash on Safety Index}

Figure 4 shows the effect of variation in plantain peel ash (PPA)on safety index for BSL and BSH compaction energies correspondingly. The safety indices varied slightly with COV for both energies. Safety indices of $-0.892,-0.892,-0.891$, $0.891,-0.891,-0.890,-0.890,-0.889,-0.889$ and -0.888 were recorded for 10, 20, 30, 40, 50, 60, 70, 80, 90 and 100\% COV respectively, for BSL compaction energy. In the case of BSH energy level, safety indices of $0.869,0.869,0.869,0.8680 .867$, $0.867,0.866,0.865,0.863$ and 0.862 were recorded for 10,20 , $30,40,50,60,70,80,90$ and $100 \%$ COV respectively. The marginal changes in the safety index values is a pointer to the fact that alteration in PPA content has little impact on the treated soil when applied for use as sub-base materials in construction of roads.

Table 2 Measured and predicted CWC values derived from model.

\begin{tabular}{|c|c|c|c|c|c|c|c|}
\hline S/No & PPA content $(\%)$ & $\begin{array}{c}\text { Compactive } \\
\text { effort }\end{array}$ & $\begin{array}{c}\text { Compactive effort } \\
\text { index }\end{array}$ & $\begin{array}{c}\text { Measured } \\
\text { CWC }\end{array}$ & $\begin{array}{l}\text { Predicted } \\
\text { CWC }\end{array}$ & $\begin{array}{c}\text { Absolute } \\
\text { Errors }\end{array}$ & $\%$ Errors \\
\hline 1 & 0 & BSL & -1 & 13.90 & 13.64 & 0.261 & 1.877 \\
\hline 2 & 2 & BSL & -1 & 12.60 & 13.36 & 0.757 & 6.009 \\
\hline 3 & 4 & BSL & -1 & 12.80 & 12.71 & 0.092 & 0.721 \\
\hline 4 & 6 & BSL & -1 & 14.20 & 12.79 & 1.408 & 9.918 \\
\hline 5 & 8 & BSL & -1 & 11.80 & 12.59 & 0.795 & 6.736 \\
\hline 6 & 10 & BSL & -1 & 11.80 & 12.01 & 0.210 & 1.777 \\
\hline 7 & 0 & $\mathrm{BSH}$ & 1 & 10.40 & 10.12 & 0.278 & 2.669 \\
\hline 8 & 2 & BSH & 1 & 9.40 & 9.84 & 0.441 & 4.686 \\
\hline 9 & 4 & BSH & 1 & 9.00 & 9.19 & 0.191 & 2.122 \\
\hline 10 & 6 & $\mathrm{BSH}$ & 1 & 9.40 & 9.27 & 0.125 & 1.331 \\
\hline 11 & 8 & $\mathrm{BSH}$ & 1 & 9.20 & 9.08 & 0.122 & 1.325 \\
\hline 12 & 10 & BSH & 1 & 8.60 & 8.49 & 0.107 & 1.244 \\
\hline
\end{tabular}




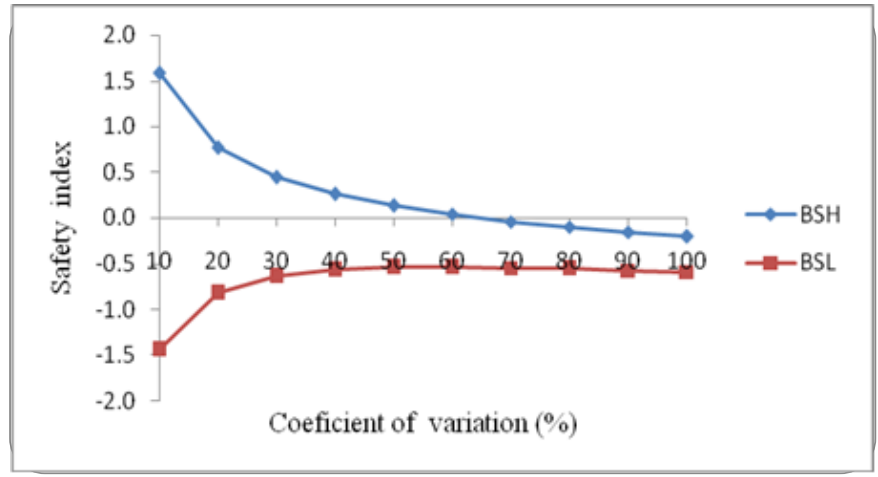

Figure 3: Changes in safety index with COV for compaction water content.

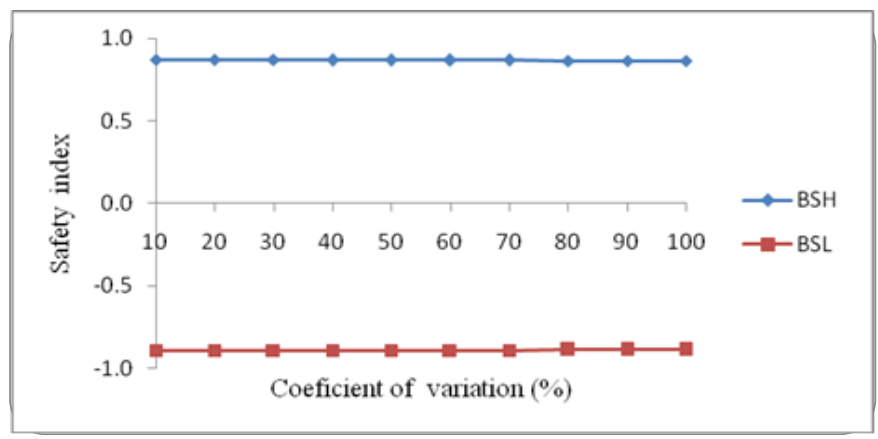

Figure 4: Changes in safety index with COV for plantain peel ash content.

\section{Influence of Plasticity Index on Safety Index}

The effect of variation in PI on safety index with changes in $\mathrm{COV}$ is displayed in Figure 5. The safety index varied slightly with changes in coefficient of variation for both BSL and BSH energy levels. Safety index values ranged between 0.896 and -0.812 for BSL compactive effort. However for BSH compactive effort, safety index values ranged between 0.861 and 0.939 as the COV rise from $10-100 \%$. The marginal increase recorded in the safety index values for both energy levels is an indication that changes in PI of the treated soil (which controls the swelling potential of the soil) has only a slight or no impact on the safety index for road pavement purposes. This presumed that plasticity index of lateritic soil treated with PPA has little effect on the performance of the road pavement.

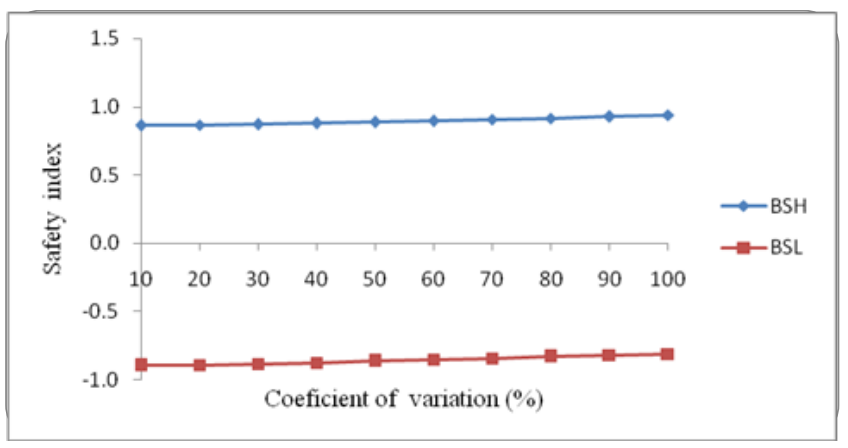

Figure 5: Changes in safety index with COV for plasticity index.

\section{Influence of Percentage Fines on Safety Index}

The outcome of safety index for percentage fines of lateritic soil - PPA mixtures with COV is displayed in Figure 6. The safety index marginally change with COV. As COV rise from 10 to $100 \%$, safety indices changed from -0.895 to -0.864 for BSL compactive effort and 0.823 to 0.875 for $\mathrm{BSH}$ compactive effort correspondingly. Changes in the percentage fine has only slight influence on the water content of compaction as shown in the deviations in safety indices. This is an indication that for lateritic soil - PPA mixtures, the percentage fine is a secondary factor that should be skilfully supervised in the course of field compaction, specification and controlled for road pavement or every geotechnical engineering application where lateritic soil - PPA mixtures are used.

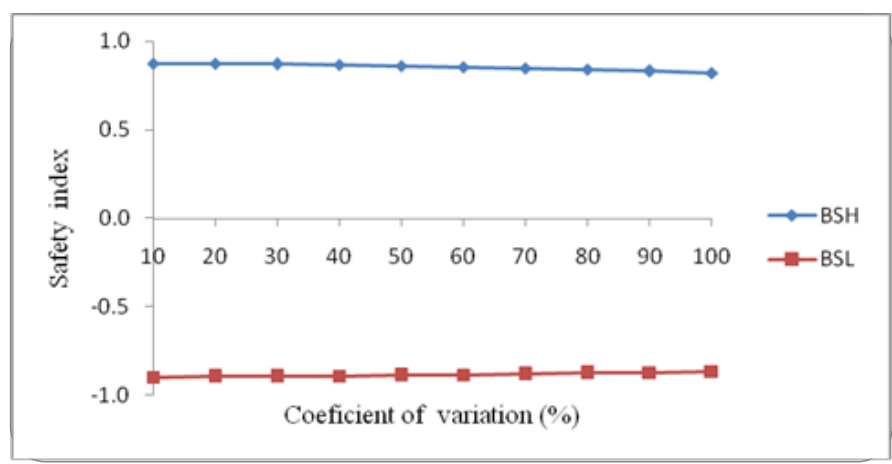

Figure 6: Changes in safety index with $\mathrm{COV}$ for percentage fine.

\section{E. Influence of Specific Gravity on Safety Index}

The differences in safety index for specific gravity of treated lateritic soil-PPA content with COV is displayed in Figure 7. Largely, safety index increased linearly with COV from 10 to $100 \%$ for BSL compaction energy, with safety index values increasing from -0.802 to -0.169 . In the case of $\mathrm{BSH}$ compaction energy, safety index values dropped significantly with safety index values reducing from 0.734 to 0.141 . Safety indices of $-0.802,-0.63,-0.488,-0.39,-0.322,-0.273,-0.237$, $-0.209,-0.187$ and -0.169 were recorded for $10,20,30,40,50$, $60,70,80,90$ and $100 \%$ coefficient of variation respectively, for BSL compaction energy.

In the case of BSH energy level, safety indices of 0.734 , $0.544,0.414,0.329,0.271,0.23,0.199,0.175,0.157$ and 0.141 were recorded for 10, 20, 30, 40, 50, 60, 70, 80, 90 and $100 \%$ coefficient of variation respectively, for BSH energy level. Safety index varied substantially for both energies which is a sign that changes in specific gravity has substantial consequence on the safety index for used in road pavement. Therefore, caution should be taken to guarantee that this factor is properly structured in the field at a regulated amount of moisture to achieve the required density in the field during road construction. 


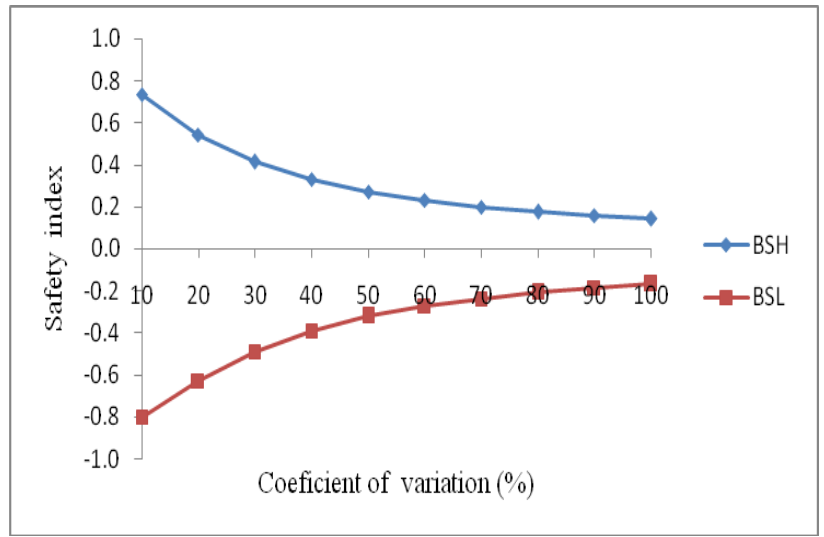

Figure 7: Changes in safety index with COV for specific gravity.

\section{F. Sensitivity of Safety Indices for BSL and BSH Compaction}

A relative sensitivity study of the safety indices of the lab based multi-linear regression model used was likened with the changes in the self-determining factors considered (PPA, PI, $\mathrm{PF}$ and Gs) to assess their influence on the compaction water content. It was generally noticed that safety indices changed for all the factors considered with Gs taking a major influence on the compaction water content than the other parameters. This is shown by the wide variation in safety indices with coefficient of variation (Figure 8 and Figure 9).PPA, PI and $\mathrm{PF}$ have marginal impact on the compaction water content of the modified soil denoted by slight changes in their safety indices with coefficient of variation. Greater safety indices were observed for BSH energy when compared to BSL energy for all the parameters studied.

For this reason, a good quality control measure for factors with major effect on the compaction water content is of significance in the course of field compaction specification and regulations when used as road pavement materials; so as to attain worthy flexible pavement materials with statistically meaningful safety index standards.

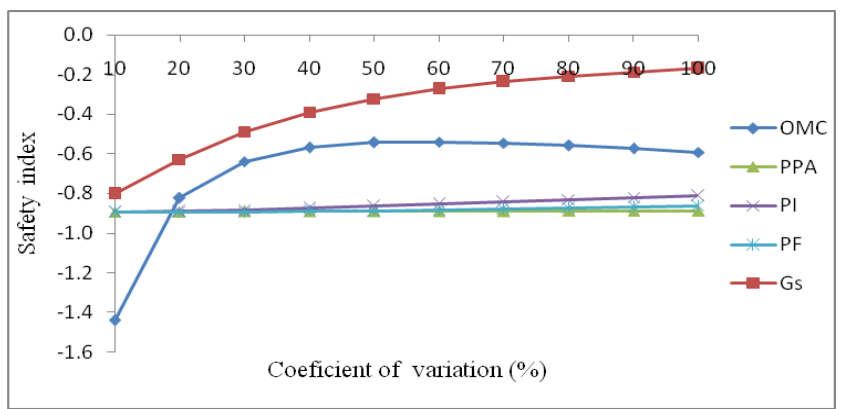

Figure 8: Changes in safety index for CWC of BSL compaction variables of lateritic-plantain peel ash mixes with COV.

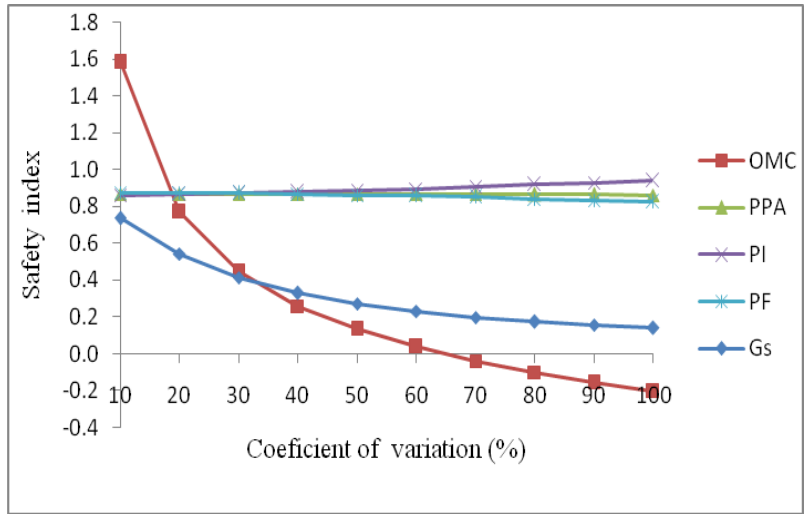

Figure 9: Changes in safety index for CWC of BSH compaction variables of lateritic-plantain peel ash mixes with $\mathrm{COV}$

\section{G. Statistical Study}

Analysis of variance in two way (ANOVA) for the safety indices of all the results obtained for the soil factors (CWC, PI, PF and Gs) with respect to plantain peel ash (PPA) produced statistically significant (SS) effect. However, few exceptions in some cases were No significant (NS) effect was recorded as displayed in Table 3, by applying F-distribution test at significance level of $95 \%$ and 5\% confidence interval. The plantain peel ash (PPA) and CE has major consequence on the results from the ANOVA test, because significant effect were recorded in most cases (see Table 3). Hence, it is vital to make sure that best blend of PPA content is added to the soil that will give rise to effective safety index values since they have been established to have influence on CWC.

\section{H. Stochastic Model Evaluation}

The safety index developed with respect to the various parameters measured are displayed in Table 4 . NCBR (NKB Report, 1978) as well as in related literatures (Yisa and Sani,2014; Yohanna and Nwaiwu,2021) stated that a safety index value of 1.0 is the required base value for serviceability limit state design of structural components. As shown in Table 4 , only $10 \%$ at BSH compaction water content met the 1.0 lowest value stated. As stated in the code and literatures safety indices of less than 1.0 is unsafe for application in structural and geotechnical engineering fields.

From the results, the lower values may be presumed to be due to the low potency of PPA to inprove the geotechnical properties of the soil to meet the minimum safety index values. Thus, the use of more potent industrial additives like cement or lime is recommended in order to produce higher safety index values of greater than 1.0. Also, higher compaction energy of BSH recorded higher and wide range of safety indices this could be linked to the packaging effect of the compaction rammer that increased the density of compacted soil. 
Table 3: Analysis of variance of safety indices.

\begin{tabular}{lcccccc}
\hline \multicolumn{1}{c}{ Property } & Source of Variation & Degree of freedom & F-value calculated & P-value & F-value calculated & SS \\
\hline Compaction water content & Compactive effort & 1 & 13.69385 & 0.004917 & 5.117355 & SS \\
Plasticity index & PPA & 9 & 0.140263 & 0.996324 & 3.178893 & NS \\
& Compactive effort & 1 & 4210248 & $7.9 \mathrm{E}-27$ & 5.117355 & SS \\
Percentage fine & PPA & 9 & 445.5488 & $7.83 \mathrm{E}-11$ & 3.178893 & SS \\
& Compactive effort & 1 & 36027.42 & $1.59 \mathrm{E}-17$ & 5.117355 & SS \\
Specific gravity & PPA & 9 & 0.067783 & 0.999775 & 3.178893 & NS \\
& Compactive effort & 1 & 29.3089 & 0.000425 & 5.117355 & SS \\
& PPA & 9 & 0.002485 & 1 & 3.178893 & NS \\
\hline
\end{tabular}

Table 4: Water content of plantain peel ash treated lateritic soil and satisfactory safety index for compaction.

\begin{tabular}{lccc}
\hline Variables Factors & \multicolumn{2}{c}{ Beta Value } & Satisfactory Range of COV (\%) \\
\cline { 2 - 3 } & BSL & BSH & \\
Compaction water content & -1.44 to -0.591 & -0.206 to 1.58 & \multirow{2}{*}{$10 \%$ BSH } \\
Plantain peel ash & -0.892 to -0.888 & 0.862 to 0.869 & Nil \\
Plasticity index & -0.896 to -0.812 & 0.861 to 0.939 & Nil \\
Percentage fine & -0.895 to -0.864 & 0.823 to 0.875 & Nil \\
Specific gravity & -0.802 to -0.169 & 0.141 to 0.734 & Nil \\
\hline
\end{tabular}

\section{CONCLUSION}

A reliability approach was used to appraise the $\mathrm{CWC}$ of lateritic soil-PPA mixtures and compacted with BSL and BSH energies, for road applications. Multi-linear regression model was established from laboratory measured data using Mini-tab R15 software which operated as a performance function for the reliability analysis. Results show that Gs and CE are affected by the change in COV and therefore must be strictly measured in lateritic soil-PPA mixes compacted with BSL and BSH energies for road pavements. It was obvious from the safety index that PPA content has minor effect and was not significantly different at all values of COV used.

Analysis of variance produced statistically significant (SS) effect with few exceptions in some cases. Gs have a more significant influence on the compaction water content than the other parameters and this is shown by the wide variation in safety indices with coefficient of variation. Stochastically, lateritic soil mixed with PPA gave adequate safety index value of 1.0 as endorsed by the NCBR at $10 \%$ COV for BSH of compaction water content only. The engineering performance and durability of roads cannot be properly explained outside the impact of the compaction water content which is greatly influenced by the factors in the model. It is thus of great significance to put these factors to use during field compaction of lateritic soil-PPA mixes to arrive at the required durable flexible pavement.

\section{REFERENCES}

Afolayan, J.O. and Abubakar, I. (2003). Reliability Analysis of Reinforced Concrete One- Way Slabs. The
Ultimate Conditions. Nigerian Journal of Engineering,11(2): $28-31$.

Dey, A. and K. K. Kudmetha. (2013). Bearing Capacity of Single Pile in Sand: Reliability Analysis using MonteCarlo Simulation.Proceedings of Indian Geotechnical Conference December 22-24, Roorkee, India.

Duncan, M. J. (2000). Factors of Safety and Reliability in Geotechnical Engineering.Journal of Geotechnical and Geo enenviromental Engineering, ASCE, 126: 307-316.

Eberemu, O. A. (2008). Evaluation of Compacted Bagasse Ash Treated Laterite Soil as Hydraulic Barriers in Waste Containment Systems. Unpublished Ph.D Dissertation Submitted to the Department of Civil Engineering, AhmaduBello University, Zaria

Eberemu, A. O. (2011). Consolidation Properties of Compacted Lateritic Soil Treated with Rice Husk Ash.Geomaterials, 1: 70-78. doi:10.4236/gm.2011.13011

Etim, R. K.; A. O. Eberemu; and K. J. Osinubi. (2017). Stabilization of Black Cotton soil with Lime and Iron Ore Tailings Admixture. Journal of Transportation Geotechnics.10:85-95.

Etim, R. K.; I. C. Attah; and P. Yohanna. (2020). Experimental Study on Potential of Oyster Shell Ash in Structural Strength Improvement of Lateritic Soil for Road Construction. International Journal of Pavement Research and Technology. DOI: https://doi.org/ 10.1007/s42947-0200290-y

Gidigasu, M. D. (1976). Laterite soil Engineering Pedogenesis and Engineering Principles. Elsevier Scientific Publication Company, Amsterderm: 444-482. 
Gui, S.; R. Zhang; J. P. Turner; and X. Zue. (2000). Probabilistic Slope Stability Analysis with Stochastic Soil Hydraulic Conductivity. Journal of Geotechnical and Geoenvironmental Engineering, ASCE, 126(1): 1-9

Harrop-Willians, K. (1985). Clay Liner Permeability: Evaluation and Variation. Journal of Geotechnical Engineering, ASCE; 111(10): 1211-1225

Ishola , K., O. A. Olawuyi; A. A. Bello; and P. Yohanna. (2019). Effect of Plantain Peel Ash on the Strength Properties of Tropical Red Soil. Nigerian Research Journal of Engineering and Environmental Sciences, 4 (1):447- 459

Kotegoda, M. and Rosso, R. (1997). Statistics, Probability, and Reliability for Civil and Environmental Engineers.New York, McGraw-Hill.

Maigen, R. (1966). Review of Research on Laterites. National Resources Research IV,United Nations Educational Scientific and Cultural Organization, Paris.

Moses, G. (2008). Stabilization of black cotton soil with ordinary Portland Cement Using Bagasse ash as admixture. IRJI Journal of Research in Engineering. 5(3):107-115

Moses, G.; and O. Folagbade. (2010). Groundnut Shell Ash Stabilization of Black Cotton Soil. Electronic Journal of Geotechnical engineering, 15: 415-42.

Muhammad, M. N. and Yamusa, B. Y. (2013). Influence of locust bean waste ash on cation exchange and plasticity characteristics of cement modified lateritic soil, American. Journal of Civil Engineering. 1 (2): 58-63.

NKB - Report No. 36. (1978). Recommendation for Loading and Safety Regulations for Structural Design.Nordic Committee on Building Regulation.

Nwaiwu, C.M.O.; J. O. Afolayan.; and K. J. Osinubi. (2009). Reliability Estimates of Field Hydraulic Conductivity of Compacted Lateritic Soils Continental. Journal of Engineering Science 4:36- 47.

Obeahon, S. O. (1993). The Effect of Elapse Time after Mixing on the Properties of Modified Laterite. Unpublished M. Sc. Thesis Civil Engineering Department Ahmadu Bello University Zaria.

Oluremi, J. R. (2015).Evaluation of Waste Wood Ash Treated Lateritic Soil for Use in Municipal Soild Waste Containment Application. Unpublished Ph.D Dissertation submitted to the Department of Civil Engineering Ahmadu Bello University, Zaria.

Oluremi, J. R.; S. T. Ijimdiya.; A. O. Eberemu and K. J. Osinubi. (2018). Reliability evaluation of hydraulic conductivity characteristics of waste wood ash treated lateritic soil. Geotechnical and Geological Engineering. https://doi.org/10.1007/s10706-018-0625-5

Oriola, F.O.P.; G. Moses.; and J. O. Afolayan. (2012). Reliability Estimates of Field Hydraulic Conductivity of Compacted Bagasse Ash Treated Foundry Sand. Journal of Environment and Earth Science 2(6): 1-13.

Osinubi, K. J. and Bajeh, I. (1994). Bituminous Stabilization of Laterite.Spectrum Journal, 1(2):104-12.

Osinubi, K. J., P. Yohanna and A. O. Eberemu. (2015). Cement Modification of Tropical Black Clay Using Iron Ore Tailings as Admixtures. Journal of Transportation
Geotechnics. 5:35-49.

http://dx.doi.org/10.1016/j.trgeo.2015.10.001.

Osinubi, K. J., A. O. Eberemu.; P. Yohanna.; and R. K. Etim. (2016). Reliability Estimate of Compaction Characteristics of Iron Ore Tailings Treated Tropical Black Clay As Road Pavement Sub-Base Material. American Society of Civil Engineers (ASCE) Geotechnical Special Publication No 271: 855-864.

Osinubi, K. J.; R. J. Oluremi.; A. O. Eberemu.; and T. S. Ijimdiya. (2017). Interaction of landfill leachate with compacted lateritic soil-waste wood ash mixture.Proceedings of the Institution of Civil Engineers.http://dx.doi.org/10.1680/jwarm.17.00012.

Phanikumar, B. R.; and R. S. Sharma. (2004). Effect of flyash on engineering properties of expansive soil.Journal of Geotechnical and Geoenvironmental Engineering. 130 (7):764-7.

Sani, J.E. (2012). Locust Bean Waste Ash Stabilization of Black Cotton Soil using Cement Kiln Dust as an Activator.Unpublished M.Sc Thesis, Civil Engineering Department, Ahmadu Bello University, Zaria, Nigeria.

Sani, J. E.; A. O. Bello.; and C. P. Nwadiogbu. (2014). Reliability Estimate of Strength Characteristics of Black Cotton Soil Pavement Sub-Base Stabilized with Bagasse Ash and CementKiln Dust. Journal of Civil and Environmental Research 6(11): 115-135

Sani, J. E.; P. Yohanna.; K. R. Etim.; J. K. Osinubi.; and O. A. Eberemu. (2017). Reliability Evaluation of Optimum Moisture Content of Tropical Black Clay Treated with Locust Bean Waste Ash as Road Pavement Sub-base Material. Journal of Geotechnical and Geological Engineering. 35(5):2421-2431. Springer International Publishing Switzerland. DOI 10.1007/s10706-017-0256-2

Sherman, G. D. (1952). The Genesis and Morphology of the Alumina rich Laterite clays. In: Clay and Laterite Genesis. Am. Inst. Min. Metal, Newyork, N.Y: 154-161.

Yisa, G. L.; and J. E. Sani. (2014). Reliability Estimate of Strength Characteristic of Iron Ore Tailing Stabilized Lateritic Soil for Road Pavement Sub-Base Materials. Engineering Journal of Geotechnical Engineering, 19: 4177-4192.

Yohanna, P.; I. Mannir.; and K. J. Osinubi. (2016). Reliability Assessment of Black Cotton Soil Stabilized with Sawdust Ash Admixtures for Use in Road Construction. Nigerian Journal of Engineering. 23(1): 44-57.

Yohanna, P.; J. R. Oluremi.; A. O. Eberemu.; K. J. Osinubi.; J. E. Sani. (2018). Reliability Assessment of Bearing Capacity of Cement-Iron Ore Tailing Blend Black Cotton Soil for Strip Foundations. Journal of Geotechnical and Geological Engineering. https://doi.org/10.1007/s10706018-0660-2

Yohanna, P. and Nwaiwu, C. M. O. (2021). Comparative Reliability Estimates of Compaction Characteristics of Sample Re-use (SR) and Fresh Sample (FS) Compaction of Lateritic soil as Road Pavement Material. Annals of Faculty of Engineering -International Journaal of Engineering. Tome XIX: 91-100. 